\title{
Noninvasive Approaches to Accelerate Orthodontic Tooth Movement: A Narrative Systemic Review
}

\author{
Poonam Majumder ${ }^{1}$, Abhishek Singh ${ }^{2}$
}

\begin{abstract}
Various methods have been adopted to reduce orthodontic treatment time. These include biological approaches using vitamin $\mathrm{D}$ and prostaglandins; relaxin cytokines that include lymphocytes and monocytes-derived factors, receptor activator of nuclear factor kappa B ligand (RANKL), etc.; surgical methods such as corticotomy, piezocision, interseptal alveolar surgery, osteotomy, etc.; and noninvasive device-assisted methods such as mechanical vibration, photobiomodulation, etc. The biological and surgical approaches although more predictable have their own limitations of acceptance by patients. The present study, therefore, is a narrative review literature on the noninvasive methods to accelerate orthodontic tooth movement. A review of 56 articles related to the studies, using noninvasive methods, was done from 1987 to 2019. Photobiomodulation is one of the most studied noninvasive methods and has shown success in reducing the treatment time. More research is needed to make these methods more accessible and patient friendly.

Keywords: Accelerated orthodontic, Diode lasers, Lasers, Noninvasive methods.

International Journal of Experimental Dental Science (2019): 10.5005/jp-journals-10029-1191
\end{abstract}

\section{INTRODUCTION}

In the present world, time is one asset that is valued by every judicious individual and the same has been recognized in the field of research in orthodontics. Orthodontic treatment is one of the most time-consuming therapies of dentistry, ${ }^{1,2}$ which leads to some adversities such as patient noncompliance and burnout, ${ }^{3}$ external root resorption, ${ }^{4,5}$ and demineralization of enamel leading to increased risk of caries. ${ }^{6,7}$ Numerous studies have been, therefore, done in this field to reduce the treatment time and the associated complications. ${ }^{8}$ This has led to the evolution of many methods to accelerate orthodontic tooth movement, which can be categorized as biological methods, biomechanical methods, and surgical methods (Flowchart 1 and Table 1). ${ }^{9-18}$

Many studies have reviewed the available methods to accelerate orthodontic tooth movement, but more focus has always been on the invasive methods, which include the biological and surgical methods. However, the noninvasive methods have the following advantages:

- Better patient compliance and acceptance.

- Reduced fear and anxiety within the patient as compared to invasive methods, because of which the routine application of invasive methods becomes difficult.

- To comply with the forthcoming deadline of social importance such as wedding, graduation, starting university, which needed to be achieved by a specific date.

- To reduce treatment time in patients who have difficulty in reaching the treatment facility due to distance, transportation problems, etc.

- Minimize the associated complications of long-term treatment such as enamel demineralization of enamel, root resorptions, etc.

This study, therefore, aims to review the literature on noninvasive methods that are available for accelerated orthodontic tooth movement and understand their effectiveness in doing the same because these noninvasive methods are more
1Private Practitioner in Dentistry, Agra, Uttar Pradesh, India

${ }^{2}$ Department of Dentistry, SNM District Hospital, Firozabad, Uttar Pradesh, India

Corresponding Author: Poonam Majumder, Private Practitioner in Dentistry, Agra, Uttar Pradesh, India, Phone: +91 8486257897, e-mail: majumderpoonam87@gmail.com

How to cite this article: Majumder P, Singh A. Noninvasive Approaches to Accelerate Orthodontic Tooth Movement: A Narrative Systemic Review. Int J Experiment Dent Sci 2019;8(2):47-50.

Source of support: Nil

Conflict of interest: None

readily accepted by the patients and hence more useful in routine practice.

Noninvasive methods for accelerated orthodontic tooth movement that have been studied in this paper include:

- Mechanical and resonance vibration

- Pulsed electromagnetic field (PEMF)

- Direct electric current

- Photobiomodulation or light accelerated orthodontics via lowlevel laser therapy (LLLT) and light-emitting diode (LED)

\section{Mechanical and Resonance Vibration}

The idea of using pulsatile forces to stimulate inflammatory reaction in bone has been studied for quite a long time in the field of both orthopedics and orthodontics. Studies conducted by Shapiro et al..$^{19}$ and Kurz et al. ${ }^{20}$ were some of the early contributors of this idea. The theories justifying the underlying working mechanism of vibratory stimulation include biological theories of increased inflammatory reaction, piezoelectric phenomenon in alveolar bone, etc. and also the biomechanical theory of reduced inelastic friction in the archwire and bracket interface. ${ }^{17}$ Alike every crystalline structure, bone also displays piezoelectric character when subjected to mechanical strain by forming electropositive (concave areas) and electronegative (convex 
areas) zones, which lead to the formation of bioelectric potential. This bioelectric potential is further increased by vibrations applied to the periodontal apparatus and thereby accelerate orthodontic tooth movement. Bowman, ${ }^{17}$ in his study, had put forward the idea that mechanical vibrations tend to reduce the inelastic friction (notching) that occurs in the bracket archwire interphase and hence reduce the treatment time. He also elucidates this reduced treatment time due to the increased inflammatory response and reduction in the "lag" phase of orthodontic tooth movement.

Various studies on animals have suggested an increased inflammatory response by increasing the mediators such as cytokines, colony-stimulating factor, interleukins, growth factors,

Flowchart 1: Pathophysiology of orthodontic tooth movement

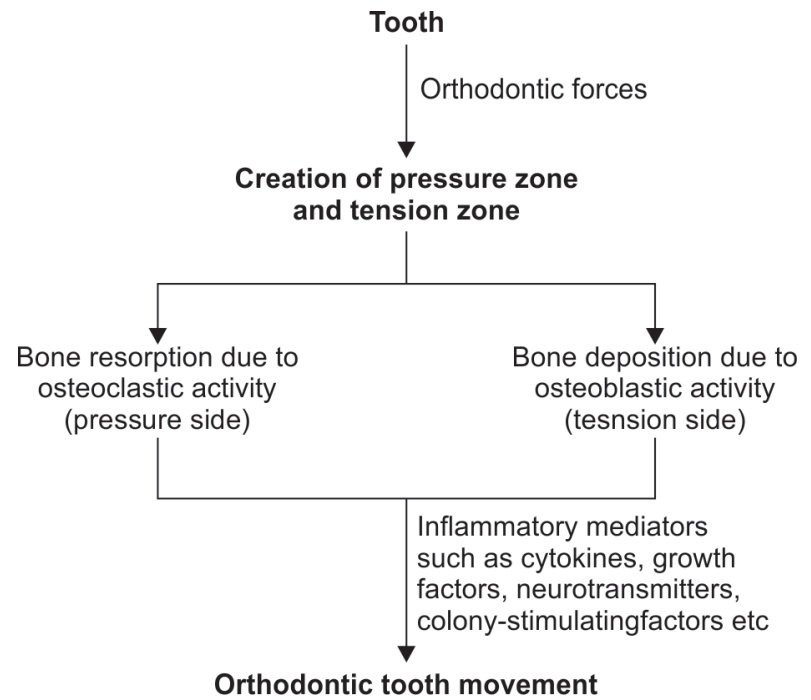

tumor necrosis factor, etc. 11,12,15,21 The studies on humans have been done by devise-assisted methods that have shown reduction in treatment time. Bowman ${ }^{17}$ and Orton-Gibbs et al. ${ }^{16}$ in their studies have used devise-assisted vibratory methods and found the time needed for alignment and leveling and reaching a bigger dimension archwire like $19 \times 25$ stainless steel or NiTi reduced by $30 \%$. It was also found that when used in conjunction with invisalign, patients reported of early change in the aligners. Kalajzic et al., ${ }^{18}$ however, did not find any significant reduction in treatment time in their study.

\section{Pulsed Electromagnetic Fields}

The PEMF has been used in orthopedics for the healing of fracture of long bones. The PEMF affects the activity of cyclic adenosine monophosphate (CAMP) and cyclic guanosine monophosphate (cGMP) by altering the cell membrane permeability. ${ }^{22}$ Table 2 enlists various studies that used this method. Darendeliler et al. ${ }^{23}$ in their study on guinea pigs observed increased rate of orthodontic tooth movement in the presence of electromagnetic field, i.e., either static or pulsed. ${ }^{24}$ Showkatbakhsh et al. ${ }^{22}$ conducted a split mouth study on 10 orthodontic patients needing canine retraction by using PEMF on one side via a circuit and watch battery. The canine retraction on the PEMF exposed side occurred faster than the contralateral side, and the difference was statistically significant. More clinical studies using PEMF needs to be done as it displays some promising result in the few studies done so far.

\section{Electrical Stimulation}

Electrical stimulation has been observed to increase cellular activity and also bone resorption and deposition activity. Table 3 enlists various studies that used this method. Davidovitch et al. ${ }^{25}$ experimented on cats by applying direct current to the anode at the pressure sites and cathode at the tension sites. This study found that electric stimulation generated local responses and acceleration of bone remodeling. Kim et al. ${ }^{26}$ in their study on seven

Table 1: Accelerated orthodontic tooth movement studies using vibration

\begin{tabular}{|c|c|c|c|c|}
\hline Author & Approach & Animal/human & Rate & Acceleration \\
\hline Kopher and $\mathrm{Mao}^{10}$ & Vibration & Rabbits & $1 \mathrm{~Hz}(5 \mathrm{~N})$ & Yes \\
\hline Peptan et al. ${ }^{11}$ & Vibration & Rabbits & $8 \mathrm{~Hz}(1 \mathrm{~N})$ & Yes \\
\hline Vij and $\mathrm{Mao}^{12}$ & Vibration & Rats & $4 \mathrm{~Hz}(300 \mathrm{nN})$ & Yes \\
\hline Nishimura et al..$^{13}$ & Vibration & Rats & $60 \mathrm{~Hz}$ (10 minutes) & Yes \\
\hline Liu et al. ${ }^{14}$ & Vibration & Mice & $4 \mathrm{~Hz}$ (5 minutes) & Yes \\
\hline Kau et al. ${ }^{15}$ & Resonance vibration & Human & 20 to $30 \mathrm{~Hz} / 20$ minutes/day & Yes \\
\hline Orton-Gibbs and Kim ${ }^{16}$ & Resonance vibration & Human & 20 to $30 \mathrm{~Hz} / 20$ minutes/day & Yes \\
\hline Bowman $^{17}$ & Resonance vibration & Human & 20 to $30 \mathrm{~Hz} / 20$ minutes/day & Yes \\
\hline Kalajzic et al. ${ }^{18}$ & Vibration & Rats & $30 \mathrm{~Hz} 10$ minutes/week & No \\
\hline
\end{tabular}

Table 2: Accelerated orthodontic tooth movement studies using pulsed electromagnetic fields

\begin{tabular}{llll}
\hline Author & Approach & Animal/human & Acceleration \\
\hline Showkatbakhsh et al. ${ }^{22}$ & Pulsed electromagnetic fields & Human & Yes \\
Darendeliler et al. $^{23}$ & Pulsed electromagnetic fields & Guinea pig & Yes \\
Stark and Sinclair & Pulsed electromagnetic fields & Guinea pig & Yes \\
\hline
\end{tabular}

Table 3: Accelerated orthodontic tooth movement studies using electric current

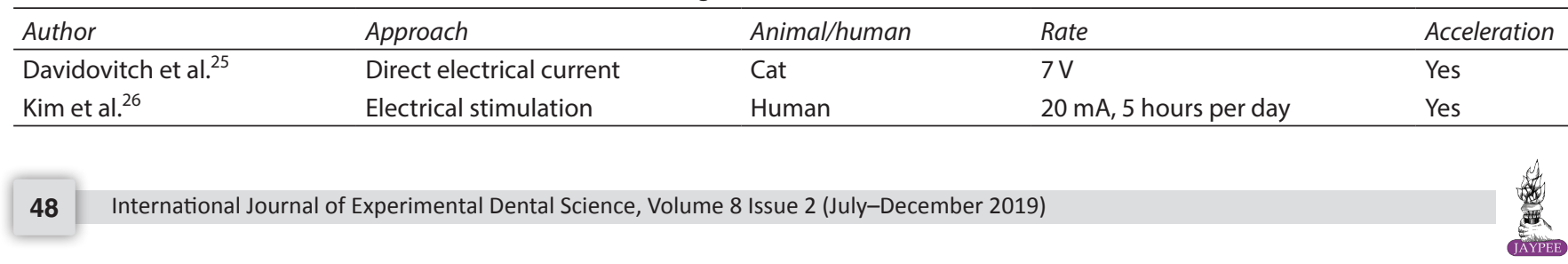


Noninvasive Approaches to Accelerate Orthodontic Tooth Movement: A Narrative Systemic Review

Table 4: Accelerated orthodontic tooth movement studies using light-accelerated orthodontics

\begin{tabular}{|c|c|c|c|c|c|}
\hline Author & Type of laser & Power output & Energy density & Wavelength $(\mathrm{nm})$ & Acceleration \\
\hline Elkattan et al. $^{21}$ & In-Ga-As & $250 \mathrm{~W} / \mathrm{cm}^{2}$ & $2,500-5,000 \mathrm{~J} / \mathrm{cm}^{2}$ & $940 \pm 10$ & Yes \\
\hline Üretürk et al. ${ }^{27}$ & Ga-Al-As & $20 \mathrm{~mW}: 10$ seconds/point & $5 \mathrm{~J} / \mathrm{cm}^{2} /$ point & 820 & Yes \\
\hline Qamruddin et al. ${ }^{28}$ & Ga-Al-As & $100 \mathrm{~mW}: 3$ seconds/point & $7.5 \mathrm{~J} / \mathrm{cm}^{2} /$ point & 940 & Yes \\
\hline Limpanichkul et al. ${ }^{29}$ & Ga-Al-As & $100 \mathrm{mw}$ & $25 \mathrm{~J} / \mathrm{sq} \cdot \mathrm{cm}$ & 850 & No \\
\hline Heravi et al. ${ }^{30}$ & Ga-Al-As & $200 \mathrm{~mW}$ & $21.4 \mathrm{~J} / \mathrm{sq} . \mathrm{cm}$ & 810 & No \\
\hline Doshi-Mehta and Bhad-Patil ${ }^{31}$ & Ga-Al-As & $100 \mathrm{nW}$ & $8 \mathrm{~J} / \mathrm{sq} . \mathrm{cm}$ & 810 & Yes \\
\hline Cruz et al. ${ }^{32}$ & Ga-Al-As & $20 \mathrm{~mW}$ & $5 \mathrm{~J} / \mathrm{sq} \cdot \mathrm{cm}$ & 780 & Yes \\
\hline Sousa et al. ${ }^{33}$ & Ga-Al-As & $20 \mathrm{~mW}$ & $5 \mathrm{~J} / \mathrm{sq} \cdot \mathrm{cm}$ & 780 & Yes \\
\hline Dalaie et al. ${ }^{34}$ & Ga-Al-As & $100 \mathrm{~mW}$ & $5 \mathrm{~J} / \mathrm{sq} \cdot \mathrm{cm}$ & 800 & No \\
\hline
\end{tabular}

female orthodontic patients used electrical current stimulation for accelerating orthodontic tooth movement. This study examined the canine retraction after first premolar extraction using miniscrew implant under the influence of direct electric stimulation.

\section{Photobiomodulation or Light-accelerated Orthodontics via LLLT and LED}

Photobiomodulation as the term implies is a process of modulation of biological tissues using light energy. Phototherapy or low-level laser therapy has been used for a variety of medical conditions, ranging from healing of ulcers, fracture, unresponsive skin cancer to reduction of pain in various circumstances. In the field of orthodontics, it has shown promising results in accelerating tooth movement, reducing pain, and relapse. Numerous studies have been done to test the effectiveness of LLLT or LED in these claims. Table 4 enlists various studies using this method. While laser is more coherent and has deeper penetration, LED is less coherent and more effective for surface treatment.

\section{Mechanism of Action}

Lasers used for treatment in medical science are the cold lasers. The photoreceptors present in the subcellular level interact in different ways to make the lasers effective. Cytochrome oxidase c, which regulates adenosine triphosphate (ATP) production, increases two-fold in response to photons from light energy in the red and infrared wavelength. Increased ATP production causes increased cellular metabolism and also increased reactive oxygen species production and mitochondrial signaling. This finally increases or suppresses transcription factors and DNA/RNA synthesis, leading to an overabundance of cellular activity.

Various clinical trials and animal studies have been done, which have mostly concluded a positive result in light-accelerated orthodontics; ${ }^{21,27,28}$ however, a few studies did not find a positive result. ${ }^{29,30-34}$ The use of different laser types of different wavelength, energy density, and power has resulted in this varying response. It has been studied that wavelength of $800-850 \mathrm{~nm}$ with lower power output of 20-100 $\mathrm{mW}$ has shown better results in increasing tooth movement. In another study done by Ojima et al., ${ }^{35}$ LED was used in continuous mode at $850 \mathrm{~nm}$ wavelength of infrared light, in conjunction with invisalign. It was found that the time in between the change of aligners significantly reduced.

\section{Conclusion}

Nonsurgical methods of accelerating orthodontic tooth movement have been discussed in this narrative review literature. Because of the heterogeneity of the data, meta-analysis has not been done. However, it can be concluded that various studies done previously to test the effectiveness of these methods have definitely shown the pathway of decreasing orthodontic treatment time. Mechanical vibrations, pulsed electromagnetic field, direct electric stimulation, and photobiomodulation have all been effective methods. However, mechanical vibration and photobiomodulation have been the methods of commercial interest and hence more marketed as devices to be readily used by practitioners. Further clinical trials are needed to achieve even better results and more cost-effective and easily available devices and methods for decreasing the orthodontic treatment time and hence the complications associated with it.

\section{References}

1. Fink DF, Smith RJ. The duration of orthodontic treatment. Am J Orthod Dentofacial Orthop 1992;102(1):45-51. DOI: 10.1016/08895406(92)70013-Z.

2. Fisher MA, Wenger RM, Hans MG. Pretreatment characteristics associated with orthodontic treatment duration. Am J Orthod Dentofacial Orthop 2010;137(2):178-186. DOI: 10.1016/ j.ajodo.2008.09.028.

3. Royko A, Denes Z, Razouk G. The relationship between the length of orthodontic treatment and patient compliance. Fogorv $\mathrm{Sz}$ 1999;92(3):79-86.

4. Segal GR, Schiffman PH, Tuncay OC. Meta analysis of the treatmentrelated factors of external apical root resorption. Orthod Craniofac Res 2004;7(2):71-78. DOI: 10.1111/j.1601-6343.2004.00286.x.

5. Pandis $\mathrm{N}$, et al. External apical root resorption in patients treated with conventional and self-ligating brackets. Am J Orthod Dentofacial Orthop 2008;134(5):646-651.

6. Geiger AM, Gorelick L, Gwinnett AJ, et al. Reducing white spot lesions in orthodontic populations with fluoride rinsing. Am J Orthod Dentofacial Orthop 1992;101(5):403-407. DOI: 10.1016/08895406(92)70112-N.

7. Bishara SE, Ostby AW. White spot lesions: formation, prevention, and treatment. Semin Orthod 2008;14:174-182. DOI: 10.1053/ j.sodo.2008.03.002.

8. Imani MM, Golshah A, Safari-Faramani R, et al. Effect of low-level laser therapy on orthodontic movement of human canine. Review/Acta Inform Med 2018;26(2):139-143. DOI: 10.5455/aim.2018.26.139-143.

9. Nimeri G, Kau CH, Abou-Kheir NS, et al. Acceleration of tooth movement during orthodontic treatment - a frontier in orthodontics. Prog Orthod 2013;14:42. DOI: 10.1186/2196-1042-14-42.

10. Kopher RA, Mao JJ. Suture growth modulated by the oscillatory component of micromechanical strain. J Bone Miner Res 2003;18(3):521-528. DOI: 10.1359/jbmr.2003.18.3.521.

11. Peptan AL, Lopez A, Kopher RA, et al. Responses of intramembranous bone and sutures upon in vivo cyclic tensile and compressive loading. Bone 2008;42(2):432-438. DOI: 10.1016/j.bone.2007.05.014.

12. Vij K, Mao JJ. Geometry and cell density of rat craniofacial sutures during early postnatal development and upon in vivo cyclic loading. Bone 2006;38(5):722-730. DOI: 10.1016/j.bone.2005.10.028. 
13. Nishimura $M$, Chiba $M$, Sato $M$, et al. Periodontal tissue activation by vibration: intermittent stimulation by resonance vibration accelerates experimental tooth movement in rats. Am J Orthod 2008;133(4):572-583. DOI: 10.1016/j.ajodo.2006.01.046.

14. Liu D, Dai Z, Royston TJ. Transmission of mechanical vibration from accele dent to dentition and skull. J Dent Res 2013;92(spec. iss. A):1773.

15. Kau CH, Nguyen JT, English JD. The clinical evaluation of a novel cyclical force generating device in orthodontics. Orthod Pract US 2010;1:10-15.

16. Orton-Gibbs S, Kim NY. Clinical experience with the use of pulsatile forces to accelerate treatment. J Clin Orthod 2015;9:14-20.

17. Bowman SJ. The effect of vibration on the rate of leveling and alignment. J Clin Orthod 2014;48:678-688.

18. Kalajzic Z, Peluso EB, Utreja A, et al. Effect of cyclical forces on the periodontal ligament and alveolar bone remodeling during orthodontic tooth movement. Angle Orthod 2014;84(2):297-303. DOI: 10.2319/032213-234.1.

19. Shapiro E, Roeber FW, Klempner LS. Orthodontic movement using pulsating force-induced piezoelectricity. Am J Orthod 1979;76(1):59-66. DOI: 10.1016/0002-9416(79)90299-9.

20. Kurz CH, Vibrational orthodontic appliance, U.S. Patent No. 4348178 , Sept. 71982.

21. Elkattan $A E$, Gheith M, Fayed MS, et al. Effects of different parameters of diode laser on acceleration of orthodontic tooth movement and its effect on relapse: an experimental animal study. Open Access Maced J Med Sci 2019;7(3):412-420. DOI: 10.3889/oamjms.2019.089.

22. Showkatbakhsh R, Jamilian A, Showkatbakhsh M. The effect of Pulsed electromagnetic fields on the acceleration of tooth movement. World J Orthod 2010;11(4):e52-e56.

23. Darendeliler MA, Sinclair PM, Kusy RP. The effects of samarium-cobalt magnets and pulsed electromagnetic fields on tooth movement. Am J Orthod 1995;107(6):578-588. DOI: 10.1016/S0889-5406(95)70100-1.

24. Stark TM, Sinclair PM. Effect of pulsed electromagnetic fields on orthodontic tooth movement. Am J Orthod 1987;91(2):91-104. DOI: 10.1016/0889-5406(87)90465-3.
25. Davidovitch Z, Finkelson MD, Steigman S, et al. Electric currents, bone remodeling, and orthodontic tooth movement. Int J Paediatr Dent 77(1):33-47. DOI: 10.1016/0002-9416(80)90222-5.

26. Kim DH, Park YG, Kang SG. The effects of electrical current from a micro-electrical device on tooth movement. Korean J Orthod 2008;38:337-346. DOI: 10.4041/kjod.2008.38.5.337.

27. Üreturk SE, Sarac M, Fıratlı S, et al. The effect of low-level laser therapy on tooth movement during canine distalization. Lasers Med Sci 2017;32(4):757-764. DOI: 10.1007/s10103-017-2159-0.

28. Qamruddin I, Alam MK, Mahroof V, et al. Effects of low-level laser irradiation on the rate of orthodontic tooth movement and associated pain with self-ligating brackets. Am J Orthod Dentofacial Orthop 2017;152(5):622-630. DOI: 10.1016/j.ajodo.2017.03.023.

29. Limpanichkul W, Godfrey K, Srisuk N, et al. Effects of low-level laser therapy on the rate of orthodontic tooth movement. Orthod Craniofac Res 2006;9(1):38-43. DOI: 10.1111/j.16016343.2006.00338.x.

30. Heravi F, Moradi A, Ahrari F. The effect of low level laser therapy on the rate of tooth movement and pain perception during canine retraction. Oral Health Dent Manag 2014;13(2):183-188.

31. Doshi-Mehta G, Bhad-Patil WA. Efficacy of low-intensity laser therapy in reducing treatment time and orthodontic pain: a clinical investigation. Am J Orthod Dentofacial Orthop 2012;141(3):289-297. DOI: 10.1016/j.ajodo.2011.09.009.

32. Cruz DR, Kohara EK, Ribeiro MS, et al. Effects of low-intensity laser therapy on the orthodontic movement velocity of human teeth: a preliminary study. Lasers Surg Med 2004;35:117-120.

33. Sousa MV, Scanavini MA, Sannomiya EK, et al. Influenceof low-level laser on the speed of orthodontic movement. Photomed Laser Surg 2011;29(3):191-196.

34. Dalaie K, Hamedi R, Kharazifard MJ, et al. Effect of low-level laser therapy on orthodontic tooth movement: a clinical investigation. $J$ Dent 2015;12(4):249-256.

35. Ojima K, Dan C, Kumagai Y. Werner Schupp: invisalign treatment accelerated by photobiomodulation. J Clin Orthod 1(5):309-316. 